\section{Antifibrinolytic drugs for acute traumatic injury}

\author{
Ian Roberts, Haleema Shakur, Katharine Ker, Tim Coats
}

The independent commentary was written by Valter Nilton Felix.

\section{ABSTRACT \\ BACKGROUND: Uncontrolled bleeding is an important cause of death in trauma victims. Antifibrinolytic treatment has been shown to reduce blood loss following surgery and may also be effective in reducing blood loss following trauma.}

OBJECTIVE: To quantify the effect of antifibrinolytic drugs in reducing blood loss, transfusion requirement and mortality after acute traumatic injury.

CRITERIA FOR CONSIDERING STUDIES FOR THIS REVIEW: We searched the Cochrane Injuries Group's Specialised Register, CENTRAL, MEDLINE, PubMed, EMBASE, Science Citation Index, National Research Register, Zetoc, SIGLE, Global Health, LILACS, and Current Controlled Trials. The Cochrane Injuries Group Specialised Register, CENTRAL, MEDLINE and EMBASE searches were updated in July 2010.

SELECTION CRITERIA: We included all randomised controlled trials of antifibrinolytic agents (aprotinin, tranexamic acid [TXA] and epsilonaminocaproic acid) following acute traumatic injury.

DATA COLLECTION AND ANALYSIS: The titles and abstracts identified in the electronic searches were screened by two independent authors to identify studies that had the potential to meet the inclusion criteria. The full reports of all such studies were obtained. From the results of the screened electronic searches, bibliographic searches, and contacts with experts, two authors independently selected trials meeting the inclusion criteria, with any disagreements resolved by consensus.

MAIN RESULTS: Four trials met the inclusion criteria. Two trials with a combined total of 20,451 patients assessed the effects of TXA on mortality; TXA reduced the risk of death by $10 \%(\mathrm{RR}=0.90,95 \% \mathrm{Cl} 0.85$ to 0.97 ; $P=0.0035)$. Data from one trial involving 20,211 patients found that TXA reduced the risk of death due to bleeding by $15 \%(R R=0.85,95 \% \mathrm{Cl} 0.76$ to $0.96 ; P=0.0077)$. There was no evidence that TXA increased the risk of vascular occlusive events or need for surgical intervention. There was no substantial difference in the receipt of blood transfusion between the TXA and placebo groups. The two trials of aprotinin provided no reliable data.

AUTHORS' CONCLUSIONS: TXA safely reduces mortality in bleeding trauma patients without increasing the risk of adverse events. Further trials are needed to determine the effects of TXA in patients with isolated traumatic brain injury.

This is the abstract of a Cochrane Review published in the Cochrane Database of Systematic Reviews (CDSR) 2011, Issue 1, DOI:1 0.1002/14651858.CD004896.pub3 (www.thecochranelibrary.com). For full citation and authors details see reference 1.

DOI: 10.1002/14651858.CD004896.pub3

For Latin America and the Caribbean, the full text is freely available

from: http://cochrane.bvsalud.org/cochrane/show.php?db=reviews\&mf n=2894\&id=CD004896\&lang=en\&dblang=\&lib=COC\&print=yes.

\section{REFERENCE}

1. Roberts I, Shakur H, Ker K, Coats T; CRASH-2 Trial collaborators. Antifibrinolytic drugs for acute traumatic injury. Cochrane Database Syst Rev. 2011;(1):CD004896.

\section{COMMENTS}

Not much data on the use of antifibrinolytic agents following acute traumatic injury is available. This Cochrane review ${ }^{1}$ aimed to prove that antifibrinolytic treatment reduces blood loss following trauma and reduces the mortality rate. The review concludes that this is true, but this conclusion is based on a single well randomized study, CRASH-2 2000. The use of tranexamic acid (TXA) reduced the mortality rate with no apparent increased risk of vascular occlusive events.

This evidence will tend to promote wider use of TXA, in relation to aprotinin and epsilon-aminocaproic acid, over the first hours of attending to cases of bleeding trauma. New counter-checks can then be published, thereby increasing our knowledge and constituting new evidence.

Valter Nilton Felix. Professor of Surgery, Faculdade de Medicina da Universidade de São Paulo (FMUSP); and Specialist in Intensive

Medicine, Associação Médica Brasileira (AMB) and Federación Panamericana e Ibérica de Sociedades de Medicina Crítica y Terapia Intensiva (FEPIMCTI). 


\section{Maternal positions and mobility during first stage labour}

\author{
Annemarie Lawrence, Lucy Lewis, G Justus Hofmeyr, \\ Therese Dowswell, Cathy Styles
}

The independent commentary was written by Wagner José Gonçalves

\begin{abstract}
BACKGROUND: It is more common for women in the developed world, and those in low-income countries giving birth in health facilities, to labour in bed. There is no evidence that this is associated with any advantage for women or babies, although it may be more convenient for staff. Observational studies have suggested that if women lie on their backs during labour this may have adverse effects on uterine contractions and impede progress in labour.

OBJECTIVE: The purpose of the review is to assess the effects of encouraging women to assume different upright positions (including walking, sitting, standing and kneeling) versus recumbent positions (supine, semi-recumbent and lateral) for women in the first stage of labour on length of labour, type of delivery and other important outcomes for mothers and babies.
\end{abstract}

CRITERIA FOR CONSIDERING STUDIES FOR THIS REVIEW: We searched the Cochrane Pregnancy and Childbirth Group's Trials Register (November 2008).

SELECTION CRITERIA: Randomised and quasi-randomised trials comparing women randomised to upright versus recumbent positions in the first stage of labour.

DATA COLLECTION AND ANALYSIS: We used methods described in the Cochrane Handbook for Systematic Reviews of Interventions for carrying out data collection, assessing study quality and analysing results. A minimum of two review authors independently assessed each study. MAIN RESULTS: The review includes 21 studies with a total of 3706 women. Overall, the first stage of labour was approximately one hour shorter for women randomised to upright as opposed to recumbent positions (MD - $0.99,95 \% \mathrm{Cl}-1.60$ to -0.39). Women randomised to upright positions were less likely to have epidural analgesia (RR $0.8395 \% \mathrm{Cl} 0.72$ to 0.96 ). There were no differences between groups for other outcomes including length of the second stage of labour, mode of delivery, or other outcomes related to the wellbeing of mothers and babies. For women who had epidural analgesia there were no differences between those randomised to upright versus recumbent positions for any of the outcomes examined in the review. Little information on maternal satisfaction was collected, and none of the studies compared different upright or recumbent positions. AUTHORS' CONCLUSIONS: There is evidence that walking and upright positions in the first stage of labour reduce the length of labour and do not seem to be associated with increased intervention or negative effects on mothers' and babies' wellbeing. Women should be encouraged to take up whatever position they find most comfortable in the first stage of labour.

This is the abstract of a Cochrane Review published in the Cochrane Database of Systematic Reviews (CDSR) 2009, Issue 2, DOI:10.1002/14651858.CD003934.pub2 (www.thecochranelibrary.com). For full citation and authors details see reference 1 .

DOI: 10.1002/14651858.CD004896.pub2
For Latin America and the Caribbean, the full text is freely available

from: http://cochrane.bvsalud.org/cochrane/show.php?db=reviews\&mf

n=2201\&id=CD003934\&lang=en\&dblang=\&lib=COC\&print=yes

\section{REFERENCE}

1. Lawrence A, Lewis L, Hofmeyr GJ, Dowswell T, Styles C. Maternal positions and mobility during first stage labour. Cochrane Database Syst Rev. 2009;(2):CD003934.

\section{COMMENTS}

This excellent systematic review, ${ }^{1}$ considering a total of 3706 women, compared upright versus recumbent positions during the first stage of labor.

The authors concluded there were no differences between the groups regarding the type of delivery or other outcomes relating to the wellbeing of mothers and babies. Furthermore, there was evidence that walking or remaining in an upright position during the first stage of labor reduced the length of labor.

Wagner José Gonçalves. Full Professor in the Department of Gynecology, Universidade Federal de São Paulo (Unifesp), São Paulo, Brazil. 